\title{
Natural history of inflammatory bowel disease: a comparison between the East and the West
}

\author{
Eun Mi Song ${ }^{1}$, Suk-Kyun Yang ${ }^{2}$ \\ ${ }^{1}$ Department of Internal Medicine, Ewha Womans University College of Medicine, Seoul; ${ }^{2}$ Department of Gastroenterology, Asan Medical \\ Center, University of Ulsan College of Medicine, Seoul, Korea
}

Over the past decades, there has been a rapid increase in the incidence and prevalence of inflammatory bowel disease (IBD) in Asia. The natural history of IBD in Asian patients could be different from that in Western patients due to variations in disease phenotypes and genotypes as well as the healthcare environment between the 2 populations. To adequately cope with this disease, it is important to fully understand the potential differences in its natural history among different populations. In this review, we evaluated the differences in the clinical course of IBD between Asian and Western patients with regards to phenotypic progression, hospitalization, major surgery, risk of colorectal cancer, and mortality, mainly based on the results of populationbased studies. The findings of our narrative review suggest that the clinical course of Asian patients with IBD, especially ulcerative colitis, is better than that of Western patients, as indicated by the lower rates of major surgery and hospitalization. In addition, similar to Western patients, the clinical course of Asian patients with IBD has been improving as evidenced by the decreasing rates of disease behavior progression (in Crohn's disease), hospitalization, and major surgery. (Intest Res 2022;20:418-430)

Key Words: Inflammatory bowel disease; Asia; Prognosis

\section{INTRODUCTION}

Inflammatory bowel disease (IBD) was previously considered a rare disease in Asia. However, over the past few decades, there has been a rapid increase in its incidence and prevalence, posing a substantial healthcare burden in this area. ${ }^{1-4}$ Characteristics of IBD in Asian populations are known to be different from those in Western populations in many aspects. ${ }^{5}$ Therefore, to adequately cope with this chronic and progressive disease, it is important to fully understand the unique clinical course of IBD in Asian populations.

The clinical course of IBD may be influenced by many factors, including disease phenotypes and genotypes, delays in

Received July 28, 2021. Revised September 9, 2021

Accepted September 20, 2021.

Correspondence to Suk-Kyun Yang, Department of Gastroenterology, Asan

Medical Center, University of Ulsan College of Medicine, 88 Olympic-ro 43-

gil, Songpa-gu, Seoul 05505, Korea. Tel: +82-2-3010-3901, Fax: +82-2-

2045-4043, E-mail: sky@amc.seoul.kr diagnosis and treatment, patient response to medications, and changes in treatment paradigms. Therefore, when comparing the outcomes of IBD between Asian and Western patients, it should be noted that the following characteristics or conditions surrounding Asian IBD may affect result interpretation. First, Asian patients have distinct phenotypic characteristics including a higher prevalence of perianal fistulas in Crohn's disease (CD) and a higher proportion of proctitis in ulcerative colitis (UC) compared with Western patients. ${ }^{6}$ Regarding genotypes, NOD2 is strongly associated with CD in Caucasians but does not demonstrate any association in Asians. In contrast, TNFSF15 has much larger effects on CD risk in Asians than in Caucasians. ${ }^{7}$ Second, the low awareness of IBD by physicians and the general population due to low disease prevalence, limited access to medical care, and high prevalence of infectious enterocolitis mimicking IBD (particularly intestinal tuberculosis $)^{8}$ may lead to delays in the diagnosis and treatment of IBD in many Asian countries. Previous Asian studies 
reported that $27 \%-45 \%$ of patients with CD received anti-tuberculosis therapy before they were finally diagnosed with $\mathrm{CD}$ because of the difficulty in differentiating between $\mathrm{CD}$ and intestinal tuberculosis, resulting in diagnostic delay and increased risk of stenotic complications. ${ }^{9,10}$ In addition, the high prevalence of infectious diseases, including hepatitis B virus infection, ${ }^{11,12}$ tuberculosis, ${ }^{13,14}$ and cytomegalovirus colitis, ${ }^{15,16}$ in Asian countries may adversely affect the treatment of IBD. Third, there may be racial differences in the medication response and the adverse events associated with medications. Thiopurine-induced acute severe leukopenia is more common in Asians than in Caucasians because of the higher prevalence of NUDT15 variants, limiting the use of thiopurines in Asians. ${ }^{17-19}$ In contrast, previous studies have suggested that the response to biologic agents, such as infliximab, ${ }^{20-22}$ adalimumab, ${ }^{23-25}$ vedolizumab, ${ }^{26-28}$ and ustekinumab, ${ }^{29}$ does not differ between Asian and Western patients with IBD. Fourth, although the introduction of biologic agents has dramatically changed the paradigm of IBD treatment and they may be equally efficacious in Asian and Western patients, their use in Asian countries is limited because of the high cost and the generally unpermitted top-down therapy. Accordingly, a simple comparison of disease outcomes, such as surgical rates, without considering the confounding effects of the aforementioned fac-

Table 1. Outcomes of Patients with Ulcerative Colitis in Asian Population-Based Studies in Contrast to a Systematic Review and MetaAnalysis from Western Population-Based Studies

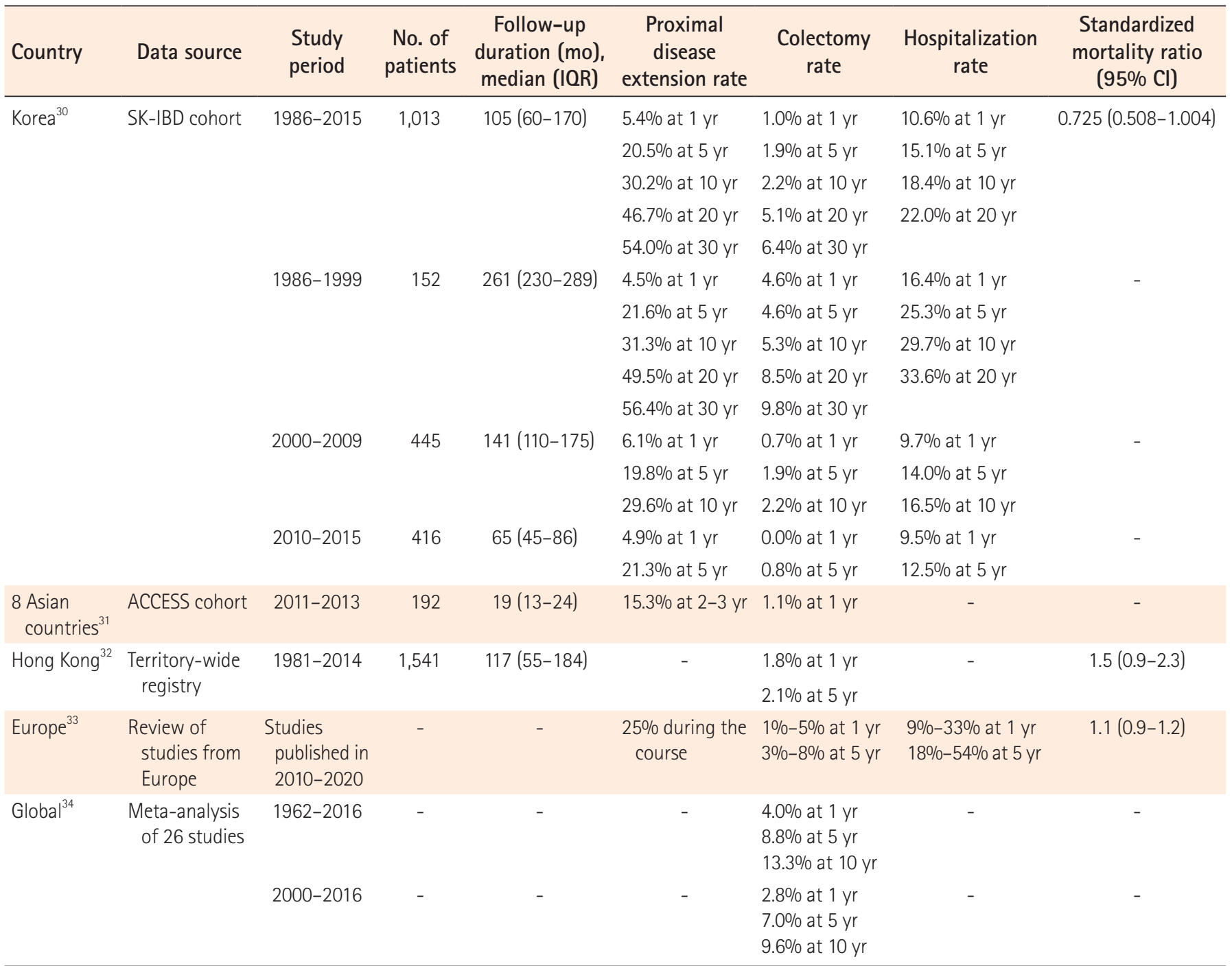

IQR, interquartile range; Cl, confidence interval; SK-IBD, Songpa-Kangdong Inflammatory Bowel Disease; ACCESS, Asia-Pacific Crohn's and Colitis Epidemiology Study. 
tors, may lead to false conclusions on the prognosis of Asian patients with IBD.

In this review, we aimed to evaluate how the clinical course of IBD in Asian patients differs from that in Western patients and investigate whether there are temporal trends toward improvement in the clinical course of Asian patients with IBD.

\section{METHODS}

\section{Outcomes of Interest}

To describe the natural history of IBD in Asian patients, we evaluated several IBD-related outcomes including phenotypic progression, hospitalization, major surgery, risk of colorectal

Table 2. Outcomes of Patients with Crohn's Disease in Asian Population-Based Studies in Contrast to a Systematic Review and MetaAnalysis from Western Population-Based Studies

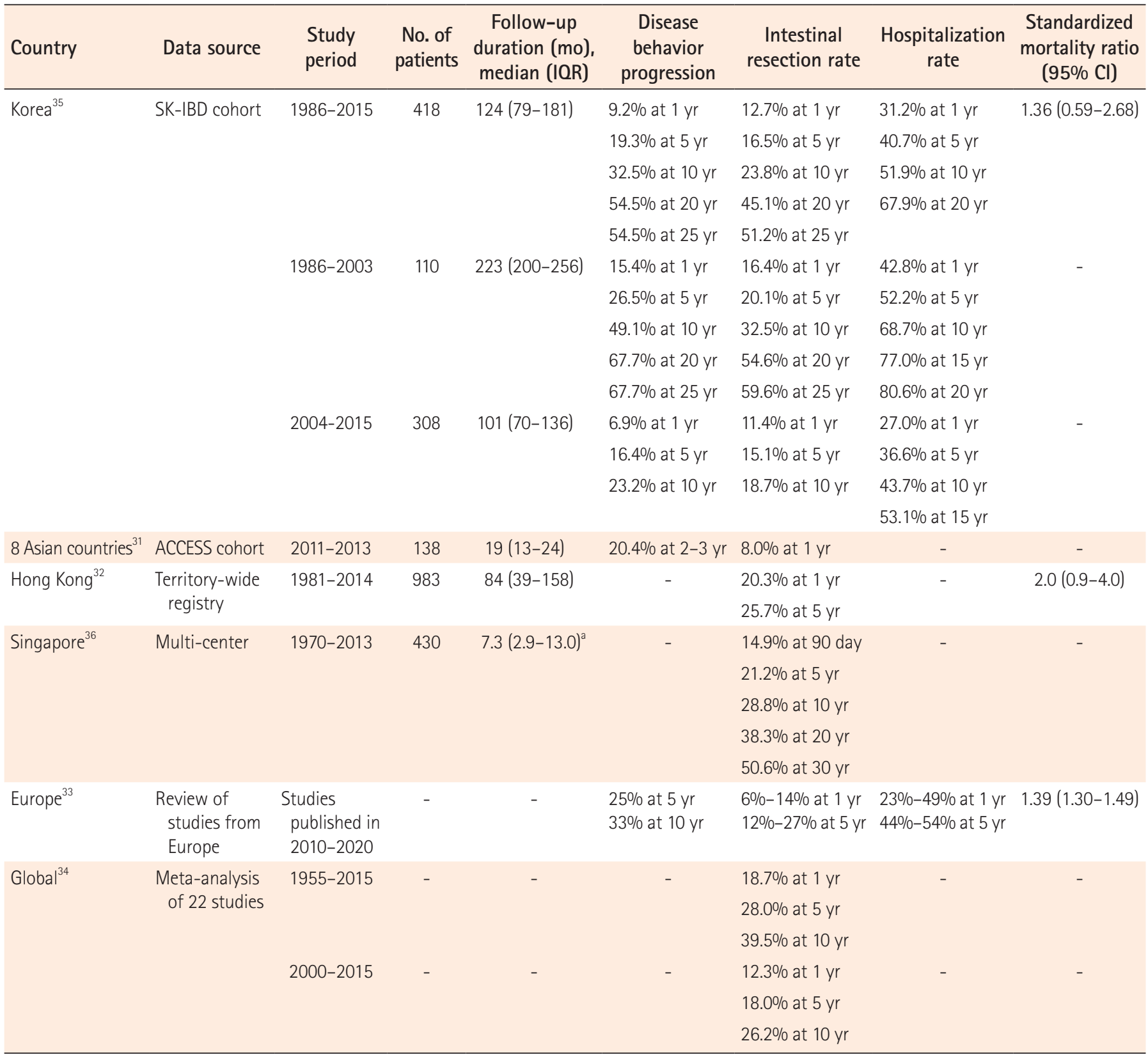

${ }^{\mathrm{a}} 7.3 \mathrm{yr}(2.9-13.0)$.

IQR, interquartile range; $\mathrm{Cl}$, confidence interval; SK-IBD, Songpa-Kangdong Inflammatory Bowel Disease; ACCESS, Asia-Pacific Crohn's and Colitis Epidemiology Study. 
cancers, and mortality. Moreover, when data is available, the temporal trends of IBD-related clinical outcomes in Asian patients with IBD were assessed. The outcomes of these Asian studies were compared with those of Western populationbased cohort studies (Tables 1-3). If necessary, results from hospital-based studies were mentioned.

\section{Literature Search}

We conducted a systematic literature search in MEDLINE using the PubMed database to identify mainly population-based studies and, in case of lacking population-based studies, hospital-based studies from Asian countries which reported the natural history of IBD patients. We searched for the following terms: ("inflammatory bowel disease" OR "ulcerative colitis" OR "Crohn's disease") AND ("population-based" OR "nationwide") AND ("natural history" OR "natural course" OR "longterm outcome" OR "long-term follow-up" OR "temporal trend" OR "temporal change" OR "phenotype" OR "progression" OR "extension" OR "surgery" OR "resection" OR "colectomy" OR "perianal" OR "fistula" OR "hospitalization" OR "cancer" OR "malignancy" OR "mortality"). Studies from Asian populationbased cohorts, including the Songpa-Kangdong Inflammatory Bowel Disease (SK-IBD) cohort, ${ }^{1,30,35}$ the Asia-Pacific Crohn's and Colitis Epidemiology Study (ACCESS) cohort, ${ }^{31}$ and the Hong Kong IBD Registry ${ }^{32,37,38}$ investigated various outcomes of both UC and CD, and were included in this review. In addition, several population-based studies from Asia evaluating a single-parameter outcome were included. ${ }^{36,39-42}$

\section{RESULTS}

\section{Phenotypic Progression 1) $U C$}

The extent of disease upon UC diagnosis is known to be different between Western and Asian patients. In a systematic review of 17 population-based cohorts, ${ }^{43}$ the most common disease presentation at diagnosis was left-sided colitis (median, $40.1 \%$; interquartile range [IQR], 32.6\%-44.6\%), followed by extensive colitis (30.5\%; IQR, 29.8\%-32.6\%) and proctitis $(29.4 \%$; IQR, 25.3\%-34.7\%). In contrast, in the SK-IBD cohort, the most common disease presentation at diagnosis was proctitis (54.3\%), followed by extensive colitis (23.2\%) and left-sided colitis (22.5\%). Similarly, in the ACCESS cohort with patients from 8 Asian countries, disease presentation at diagnosis was proctitis (36.5\%), extensive colitis (32.8\%), and left-sided colitis (30.7\%) in decreasing order of proportion. ${ }^{31}$

During the disease course, patients with UC experience proximal progression of the disease. Proximal disease extension appeared to carry a more severe disease course and was associated with an increased need for immunosuppressive treatment and an increased risk of hospitalization and colectomy. ${ }^{44}$ In a population-based cohort study from Veszprem Province, Hungary, the cumulative risks of proximal disease extension at 1, 3, 5 years after the diagnosis of ulcerative proctitis or left-sided colitis were $2.9 \%, 9.4 \%$, and $12.7 \%$, respectively. ${ }^{45}$ In a European population-based inception cohort (the Epi-IBD cohort), 90 (20.7\%) of 435 patients with proctitis or

Table 3. Comparison of Outcomes of Patients with Inflammatory Bowel Disease between the East and the West along with the Temporal Trends

\begin{tabular}{|c|c|c|c|c|}
\hline & \multicolumn{2}{|c|}{ Ulcerative colitis } & \multicolumn{2}{|c|}{ Crohn's disease } \\
\hline & East vs. West & Temporal trends & East vs. West & Temporal trends \\
\hline \multirow{2}{*}{$\begin{array}{l}\text { Phenotypic } \\
\text { progression }^{\text {a }}\end{array}$} & \multirow[t]{2}{*}{ Similar } & East: not decreasing & \multirow[t]{2}{*}{ Similar } & East: decreasing \\
\hline & & West: not decreasing & & West: conflicting \\
\hline \multirow[t]{2}{*}{ Hospitalization } & \multirow[t]{2}{*}{ East: lower } & East: decreasing & \multirow[t]{2}{*}{ Similar or East: lower } & East: decreasing \\
\hline & & West: decreasing & & West: decreasing \\
\hline \multirow[t]{2}{*}{ Major surgery } & \multirow[t]{2}{*}{ East: lower } & East: decreasing & \multirow[t]{2}{*}{ Similar or East: lower } & East: decreasing \\
\hline & & West: decreasing & & West: decreasing \\
\hline \multirow[t]{2}{*}{ Colorectal cancer } & East: insufficient data & East: no data & East: insufficient data & East: no data \\
\hline & West: SIR of $2.4(95 \% \mathrm{Cl}, 2.1-2.7)$ & West: decreasing RR & West: SIR of $1.9(95 \% \mathrm{Cl}, 1.4-2.5)$ & West: not decreasing RR \\
\hline \multirow[t]{2}{*}{ Mortality } & East: insufficient data & East: no data & East: insufficient data & East: no data \\
\hline & West: SMR of 1.1 (95\% Cl, 0.9-1.2) & West: decreasing HR & West: SMR of 1.39 (95\% Cl, 1.30-1.49) & West: not decreasing HR \\
\hline
\end{tabular}

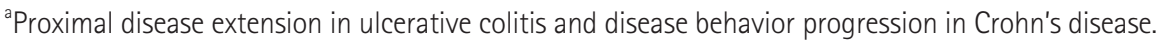

$\mathrm{SIR}$, standardized incidence ratio; SMR, standardized mortality ratio; $\mathrm{Cl}$, confidence interval; $\mathrm{RR}$, relative risk; HR, hazard ratio. 
left-sided colitis at diagnosis experienced proximal disease extension during the first 5 years of follow-up. ${ }^{46}$ In a Danish population-based inception cohort, 72 (32.7\%) of 220 patients with proctitis or left-sided colitis at diagnosis experienced proximal disease extension during the median follow-up of 7.5 years. ${ }^{47}$ Additionally, in a population-based inception cohort of SouthEastern Norway (the IBSEN cohort), 100 (34.7\%) of 288 patients with proctitis or left-sided colitis at diagnosis experienced proximal disease extension during the first 10 years of followup. ${ }^{48}$ Meanwhile, in a meta-analysis of 30 studies including both population-based and hospital-based studies and both Western and Asian studies, the cumulative risk of proximal disease extension was 17.8\% (95\% confidence interval [CI], $12.3-25.1)$ at 5 years and $31.0 \%(95 \% \mathrm{CI}, 23.5-39.7)$ at 10 years. ${ }^{49}$ In a population-based cohort study from Orebro, Sweden, between 1963 and 2010, there was no difference in the risk of proximal disease extension among the 3 temporal cohorts. ${ }^{50}$

In the SK-IBD cohort, the cumulative risks of proximal disease extension at 5, 10, 20, and 30 years after the diagnosis of ulcerative proctitis or left-sided colitis were $20.5 \%, 30.2 \%, 46.7 \%$, and $54.0 \%$, respectively. ${ }^{30}$ The risks of proximal disease extension were significantly higher in patients with proctitis than in those with left-sided colitis at diagnosis and did not differ among the 3 temporal cohorts. ${ }^{30}$ In the ACCESS cohort, the cumulative risk of proximal disease extension in Asian patients was $15.3 \%$ at $2-3$ years after diagnosis. ${ }^{31}$ Taken together, the risk of proximal disease extension in Asian patients is comparable with that in Western patients. However, it remains unknown whether any treatment can reduce the risk of proximal disease extension. The results of the SK-IBD cohort study showing no change in the risk of proximal disease extension between 1986 and 2015 raise questions about the role of any treatment in reducing the risk of proximal disease extension. Further studies using standardized approaches are required to investigate proximal disease extension.

\section{2) $C D$}

Although the most common disease behavior at $\mathrm{CD}$ diagnosis is inflammatory behavior, Western population-based cohort studies have demonstrated that $15 \%-35 \%$ of patients with CD already had stricturing or penetrating behavior at the time of CD diagnosis. ${ }^{45,51-57}$ In the SK-IBD cohort, disease behavior at CD diagnosis was inflammatory in $81.1 \%$, stricturing in $8.1 \%$, and penetrating in $10.8 \%{ }^{1}$ In a population-based cohort study from Singapore, disease behavior at CD diagnosis was inflammatory in $78.1 \%$, stricturing in $14.0 \%$, and penetrating in $7.9 \%{ }^{36}$
In the ACCESS cohort, disease behavior at CD diagnosis was inflammatory in $68.1 \%$, stricturing in $18.8 \%$, and penetrating in $13.0 \%{ }^{31}$ Perianal fistulas are common manifestations of CD and are known to be a predictor of poor prognosis. Perianal fistulas are considered more common in Asian patients with CD than in Western patients with $\mathrm{CD}^{58}$ In Western population-based cohort studies, $8.1 \%-16.7 \%$ of patients with CD developed a perianal fistula before or at $\mathrm{CD}$ diagnosis. ${ }^{59-64}$ In contrast, $43.3 \%$ and $33.3 \%$ of patients with CD developed a perianal fistula before or at CD diagnosis in the SK-IBD cohort and a Korean nationwide population-based cohort study using the National Health Insurance claims data, ${ }^{39}$ respectively. In addition, in the Hong Kong IBD Registry, 20.9\% of patients with $\mathrm{CD}$ had perianal $\mathrm{CD}$ before or at $\mathrm{CD}$ diagnosis. ${ }^{38}$

In population-based cohort studies from Europe, $14 \%-22 \%$ of patients with $\mathrm{CD}$ who had an inflammatory behavior at diagnosis experienced disease behavior progression during the first 5 years after diagnosis. ${ }^{51,52,65}$ In a population-based cohort study from Olmsted County, the cumulative risks of disease behavior progression at 1, 5, 10, 20, and 30 years after the diagnosis of CD with inflammatory behavior were $4.1 \%, 18.5 \%$, $24.7 \%, 39.5 \%$, and $43.9 \%$, respectively. ${ }^{60}$ Regarding the temporal trends of disease behavior progression, the Dutch IBD South Limburg cohort failed to show any changes between 1991 and $2011{ }^{65}$ However, in a population-based inception cohort from Western Hungary, the 5-year cumulative risk of disease behavior progression significantly decreased from $35.5 \%$ in the 1977 1989 cohort to $15.2 \%$ in the $1999-2008$ cohort. ${ }^{66}$ Regarding perianal fistulas, in Western population-based cohort studies, $13.9 \%-28.1 \%$ of patients with CD developed perianal fistulas during the median follow-up of 8.4-16.2 years after CD diagnosis. ${ }^{59-62,67,68}$ In the Dutch IBD South Limburg cohort, the cumulative risks of developing a perianal fistula at 1,5 , and 10 years after CD diagnosis were $8.3 \%, 11.6 \%$, and $15.8 \%$, respectively. ${ }^{67}$ In a population-based cohort study from Olmsted County, the cumulative risks of developing a perianal fistula at $1,5,10,20$, and $30-40$ years after CD diagnosis were $11 \%, 15 \%$, $18 \%, 23 \%$, and $24 \%$, respectively. ${ }^{61}$

In the SK-IBD cohort, the cumulative risks of disease behavior progression at $1,5,10$, and 20 years after the diagnosis of CD with inflammatory behavior were $9.2 \%, 19.3 \%, 32.5 \%$, and $54.5 \%$, respectively. ${ }^{35}$ Compared with the $1986-2003$ cohort, the 2004-2015 cohort had significantly lower cumulative risks of progression: $6.9 \%, 16.4 \%$, and $23.2 \%$ at 1,5 , and 10 years, respectively. ${ }^{35}$ In the ACCESS cohort, the cumulative risk of behavioral progression in Asian patients was $20.4 \%$ at 2-3 years 
after diagnosis. ${ }^{31}$ Taken together, there appears to be no difference in the risk of disease behavior progression between Asian and Western patients with CD. As for perianal fistulas, in a population-based cohort study using the National Health Insurance claims data, $39.2 \%$ of patients with CD developed a perianal fistula during the median follow-up of 4.2 years after CD diagnosis. ${ }^{39}$ The cumulative risks of developing a perianal fistula at 1 and 5 years after CD diagnosis were $35.2 \%$ and $40.0 \%$, respectively. In addition, in the Hong Kong IBD Registry, 28.8\% of patients with $\mathrm{CD}$ had perianal disease during the median follow-up of 8.8 years after CD diagnosis. ${ }^{38}$

\section{Hospitalization}

\section{1) $U C$}

In a recent review of European population-based cohort studies, the 1- and 5-year hospitalization rates in patients with UC were $9 \%-33 \%$ and $18 \%-54 \%$, respectively. ${ }^{33}$ Hospitalization rates varied substantially among different European countries. ${ }^{33}$ In the Olmsted County cohort, the cumulative risk of hospitalization at $5,10,20$, and 30 years after UC diagnosis was $29.4 \%$, $38.7 \%, 49.2 \%$, and $52.3 \%$, respectively. ${ }^{69}$ In addition, the rate of hospitalization in the Olmsted County cohort decreased from 134/1,000 patient-years in 1970-1979 to 88/1,000 patient-years in 2000-2004. ${ }^{69}$

In the SK-IBD cohort, the cumulative risks of hospitalization at 1,5 , and 10 years after UC diagnosis were $10.6 \%, 15.1 \%$, and $18.4 \%$, respectively. ${ }^{30}$ The cumulative risk of hospitalization was significantly lower in the recent cohort than in the older cohort, with the 5-year cumulative risk of hospitalization being $25.3 \%$ in the $1986-1999$ cohort and $12.5 \%$ in the $2010-2015$ cohort. This temporal trend of decreasing hospitalization rate was also observed in a hospital-based cohort study from Thailand, where the cumulative risks of hospitalization at 1 and 5 years after diagnosis were $18 \%$ and $30 \%$, respectively, in the 2000-2009 cohort and 5\% and 21\%, respectively, in the 2010 2018 cohort. $^{70}$ Furthermore, considering the absolute risks of hospitalization, it appears that Asian patients with UC have lower risks compared with Western patients. However, this does not necessarily mean that Asian patients experience a less severe disease form because the hospitalization rate is influenced by many factors other than disease severity, such as accessibility to healthcare services.

\section{2) $C D$}

In a recent review of European population-based cohort studies, the 1- and 5-year hospitalization rates in patients with CD were $23 \%-49 \%$ and $44 \%-54 \%$, respectively. ${ }^{33}$ In the Olmsted County cohort, 120 (57\%) of 211 patients with CD had at least 1 CD-related hospitalization during the total observation period of 2,247 patient-years. ${ }^{71}$ In the Dutch IBD South Limburg cohort, the risk of hospitalization in patients with CD significantly decreased over time, with the 5-year cumulative risk of hospitalization being $65.9 \%$ in the 1991-1998 cohort and $44.2 \%$ in the 2006-2011 cohort. ${ }^{65}$ In a population-based study from Ontario, Canada, CD-related hospitalizations decreased by $32 \%$ from $154 / 1,000$ patients in 2003 to $104 / 1,000$ patients in $2014{ }^{72}$

In the SK-IBD cohort, the cumulative risks of hospitalization at $1,5,10$, and 20 years after CD diagnosis were $31.2 \%, 40.7 \%$, $51.9 \%$, and $67.9 \%$, respectively. ${ }^{30}$ The cumulative risk of hospitalization was significantly lower in the recent cohort than in the older cohort, with the 5-year cumulative risk of hospitalization being $52.2 \%$ in the $1986-2003$ cohort and $36.6 \%$ in the 2004-2015 cohort. The cumulative risks of hospitalization in the SK-IBD cohort were similar to or slightly lower than those in Western population-based cohort studies. ${ }^{33,65,71,72}$

\section{Major Surgery \\ 1) $U C$}

In a meta-analysis of 26 population-based cohort studies from Europe ( $(n=17)$, North America $(n=5)$, Oceania $(n=2)$, Asia $(\mathrm{n}=1)$, and Africa $(\mathrm{n}=1)$, the cumulative risks of colectomy at 1,5 , and 10 years after UC diagnosis were $4.0 \%$ (95\% CI, 3.35.0), 8.8\% (95\% CI, 7.7-10.0), and 13.3\% (95\% CI, 11.3-15.5), respectively. ${ }^{34}$ Among patients diagnosed in the 21st century, the cumulative risks of colectomy at 1,5 , and 10 years after UC diagnosis were $2.8 \%$ (95\% CI, 2.0-3.9), 7.0\% (95\% CI, 5.7-8.6), and $9.6 \%$ (95\% CI, 6.3-14.2), respectively. There was no difference in the cumulative risk of colectomy between Europe and North America. ${ }^{34}$

Compared with Western studies, population-based cohort studies from Asia have reported very low colectomy rates. ${ }^{30-32}$ The cumulative risk of colectomy at 1 year after UC diagnosis was only $1.1 \%$ in the ACCESS cohort, ${ }^{31}$ and that at 1 and 5 years after UC diagnosis was $1.8 \%$ and $2.1 \%$, respectively, in the Hong Kong IBD Registry. ${ }^{32}$ The risk of colectomy in the SK-IBD cohort was even lower than that reported in these 2 studies. In the SK-IBD cohort, the cumulative risks of colectomy at 1,5 , 10,20 , and 30 years after UC diagnosis were $1.0 \%, 1.9 \%, 2.2 \%$, $5.1 \%$, and $6.4 \%$, respectively. ${ }^{30}$ Because the cumulative risks of colectomy significantly decreased over the study period of 1986-2015, they were even lower among patients diagnosed 
in the 21 st century: $0.4 \%$ at 1 year, $1.4 \%$ at 5 years, and $1.6 \%$ at 10 years after diagnosis. Moreover, in the 2010-2015 cohort, no patients underwent colectomy during the first year after diagnosis, and only $0.8 \%$ of patients underwent colectomy during the first 5 years after diagnosis. ${ }^{30}$

\section{2) $C D$}

In a meta-analysis of 22 population-based cohort studies from Europe $(n=16)$, North America $(n=2)$, Oceania $(n=2)$, Asia $(\mathrm{n}=1)$, and Africa $(\mathrm{n}=1)$, the cumulative risks of intestinal resection at 1,5 , and 10 years after CD diagnosis were $18.7 \%$ (95\% CI, 15.0-23.0), 28.0\% (95\% CI, 24.0-32.4), and 39.5\% (95\% CI, 33.3-46.2), respectively. ${ }^{34}$ Among patients diagnosed in the 21 st century, the cumulative risks of intestinal resection at 1, 5, and 10 years after CD diagnosis were $12.3 \%$ (95\% CI, 10.8-14.0), $18.0 \%$ (95\% CI, 15.4-21.0), and 26.2\% (95\% CI, 23.4-29.4), respectively. There was no difference in the cumulative risk of intestinal resection between Europe and North America. ${ }^{34}$ Proctectomy is required in some patients with a refractory complex perianal fistula. In a population-based cohort study from Olmsted County, the cumulative risk of proctectomy was $20 \%$ at 10 years and $22 \%$ at $20-40$ years after the diagnosis of a perianal fistula. ${ }^{61}$

In the SK-IBD cohort, the cumulative risks of intestinal resection at $1,5,10,20$, and 25 years after CD diagnosis were $12.7 \%$, $16.5 \%, 23.8 \%, 45.1 \%$, and $51.2 \%$, respectively, with a trend of decreasing risk over the study period ${ }^{30}$ In the 2004-2015 cohort, the cumulative risks of intestinal resection at 1,5 , and 10 years after CD diagnosis were $11.4 \%, 15.1 \%$, and $18.7 \%$, respectively. In a population-based study from Singapore, the cumulative risks of intestinal resection at 5, 10,20, and 30 years after CD diagnosis were $21.2 \%, 28.8 \%, 38.3 \%$, and $50.6 \%$, respectively. ${ }^{36}$ In the Hong Kong IBD Registry, the cumulative risks of intestinal resection at 1 and 5 years after $\mathrm{CD}$ diagnosis were 20.3\% and $25.7 \%$, respectively. ${ }^{32}$ The cumulative risk of intestinal resection at 1 year after CD diagnosis was the lowest at $8.0 \%$ in the ACCESS cohort. ${ }^{31}$ Taken together, the cumulative risks of intestinal resection at 1,5 , and 10 years after $\mathrm{CD}$ diagnosis in Asian population-based cohort studies were $8 \%-20 \%, 17 \%-$ $26 \%$, and $24 \%-29 \%$, respectively. These rates are comparable to or slightly lower than those of the aforementioned metaanalysis. In addition, the cumulative risks of intestinal resection in the 2004-2015 cohort of the SK-IBD cohort were comparable to or slightly lower than those in the contemporary cohorts of patients diagnosed with CD after 2000 in the metaanalysis. As for proctectomy due to a perianal fistula, in the
Hong Kong IBD Registry, the cumulative risks of defunctioning surgery and/or proctectomy at 1,3 , and 10 years after the diagnosis of a perianal fistula were $4.1 \%, 5.4 \%$, and $6.8 \%$, respectively. ${ }^{38}$ In a hospital-based cohort from Korea, the cumulative risks of proctectomy at 10, 20, and 30 years after the diagnosis of a perianal fistula were $2.9 \%, 12.2 \%$, and $16.2 \%$, respectively. ${ }^{39}$ Therefore, the risk of proctectomy in patients with $\mathrm{CD}$ who developed perianal fistulas is lower in Asian patients than in Western patients. In this Korean study, the cumulative risk of proctectomy was significantly lower in the biologic era than in the pre-biologic era. ${ }^{39}$

\section{Risk of Colorectal Cancer 1) $U C$}

In a meta-analysis of 8 Western population-based cohort studies from Europe $(n=6)$ and North America $(n=2)$, the cumulative risks of colorectal cancer were $<1.0 \%$ at 10 years, $0.4 \%-$ $2.0 \%$ at 15 years, and $1.1 \%-5.3 \%$ at 20 years after UC diagnosis, and the pooled standardized incidence ratio (SIR) for colorectal cancer was 2.4 (95\% CI, 2.1-2.7) ${ }^{73}$ In population-based cohort studies from Copenhagen and Hungary, the 30-year cumulative risks of colorectal cancer were $2.1 \%$ and $7.5 \%$, respectively ${ }^{74,75}$ In a study involving the Uppsala and Stockholm cohorts of IBD, there was a trend toward a decrease in the risk of colorectal cancer from 1960 to 2004, but it did not reach statistical significance ${ }^{76}$ However, in a study involving a nationwide cohort of Danish patients with IBD, the relative risk of colorectal cancer in patients with UC decreased significantly from 1.34 (95\% CI, 1.13-1.58) in 1979-1988 to 0.57 (95\% CI, 0.41$0.80)$ in $1999-2008 .^{77}$

Recently, 3 population-based studies from Asian countries have been published on the risk of colorectal cancer in patients with IBD. In the Hong Kong IBD Registry, during the median follow-up of 10 years, 13 of 1,603 patients with UC developed colorectal cancer, with an SIR of 0.95 (95\% CI, 0.55-1.64). ${ }^{37}$ Similarly, in a study from Taiwan, during the mean follow-up of 7.2 years, 18 of 2,663 patients with UC developed colorectal cancer, with an SIR of 1.39 (95\% CI, 0.8-2.2). ${ }^{40}$ No observed increase in the risk of colorectal cancer in these 2 studies was possibly due to the short follow-up period. In contrast, in a study from Korea utilizing the National Health Insurance claims data, during the median follow-up of 2.20 years (range, $0.00-3.99$ years), 31 of 9,785 patients with UC developed colorectal cancer, with SIRs of 2.14 (95\% CI, 1.31-3.30) for male patients and 2.95 (95\% CI, 1.47-5.29) for female patients. ${ }^{41}$ Although this Korean study demonstrated an increased risk of colorectal cancer in patients 
with UC, considering the very short follow-up period, the results of this Korean study should be interpreted with caution. According to previous Danish population-based studies, there was a remarkably high risk of colorectal cancer in the first year after IBD diagnosis, probably due to coincidental detection of recent-onset or prevalent IBD in patients diagnosed with colorectal cancer and misclassification of IBD versus cancer. ${ }^{77,78}$ Therefore, more population-based studies with a longer follow-up period are needed to verify these results. In hospitalbased cohort studies, the 30-year cumulative risk of colorectal cancer in Asian patients with UC ranged from $5.2 \%$ to $14.4 \%$, ${ }^{79.82}$ which was similar to that in previous Western studies. In a hospital-based cohort study from Korea, the SIR for colorectal cancer in patients with UC was 1.70 (95\% CI, 1.00-2.66). ${ }^{79}$

\section{2) $C D$}

In a meta-analysis of 6 population-based cohort studies from Europe $(\mathrm{n}=3)$, North America $(\mathrm{n}=2)$, and Israel $(\mathrm{n}=1)$, the pooled SIR for colorectal cancer was $1.9(95 \% \mathrm{CI}, 1.4-2.5){ }^{83} \mathrm{In}$ a study involving a nationwide cohort of Danish patients with IBD, the relative risk of colorectal cancer in patients with CD was lower than previously known (relative risk, $0.85 ; 95 \% \mathrm{CI}$, 0.67-1.07) and, in contrast to UC, did not decrease significantly from 1979 to 2008 . $^{77}$

In the 3 Asian population-based cohort studies, the SIRs for colorectal cancer in patients with CD were 1.64 (95\% CI, 0.743.65) in Hong Kong, ${ }^{37} 0.96$ (95\% CI, 0.1-3.5) in Taiwan, ${ }^{40}$ and 3.67 (95\% CI, 1.58-7.22) for males and 4.67 (1.52-10.90) for females in Korea. ${ }^{41}$ These results have problems similar to that in UC. In a hospital-based cohort study from Korea, the SIR for colorectal cancer in patients with CD was 6.0 (95\% CI, 3.1010.48). ${ }^{79}$ Of note, in all 6 patients who developed colorectal cancer in the Hong Kong IBD Registry, the cancer was located in the anorectum. ${ }^{37}$ Similarly, in hospital-based cohort studies from Korea ${ }^{79}$ and Japan, ${ }^{84,85}$ the colorectal cancer was located in the rectum in $89 \%-100 \%$ of patients with CD and colorectal cancer, in contrast with only $40 \%$ in Western studies. ${ }^{86}$ The high proportion of rectal cancer in Asian patients with $\mathrm{CD}$ and colorectal cancer may be partly explained by the high prevalence of perianal fistulas in this population. ${ }^{1,79,87}$

\section{Mortality}

1) $U C$

Most Western population-based cohort studies published after 2000 reported no increase in mortality in patients with UC compared with in the general population, ${ }^{88-92}$ barring some studies that reported a slight increase ${ }^{93,94}$ or decrease.$^{95}$ In a meta-analysis of 10 Western population-based cohort studies from Europe ( $(\mathrm{n}=8)$, North America $(\mathrm{n}=1)$, and Oceania $(\mathrm{n}=1)$, the pooled standardized mortality ratio (SMR) was $1.1(95 \%$ CI, 0.9-1.2) $9{ }^{96}$ In a study involving a Danish national cohort, the mortality in patients with UC was significantly higher than that in matched controls (hazard ratio, 1.25; 95\% CI, 1.22-1.28), and it decreased gradually from 1982 to $2010 .^{93}$

In the SK-IBD cohort, the cumulative survival rates at 1, 5, 10,20 , and 30 years after UC diagnosis were $99.7 \%, 98.7 \%, 96.6 \%$, $92.2 \%$, and $91.2 \%$, respectively, and the SMR was 0.725 (95\% CI, 0.508-1.004). ${ }^{30}$ In the Hong Kong IBD Registry, the SMR was 1.5 (95\% CI, 0.9-2.3). ${ }^{32}$ In contrast to these 2 Asian studies and the Western meta-analysis, a population-based study from Taiwan using the National Health Insurance database showed increased mortality in patients with UC (SMR, 1.44; 95\% CI, 1.26-1.65). ${ }^{42}$ The SMR in the Taiwanese patients with UC decreased from 1.88 (95\% CI, 1.33-2.60) in 2001-2005 to 1.36 (95\% CI, 1.11-1.65) in 2011-2015. However, the mortality rate remained higher in patients with UC than in the general population even in the most recent cohort. The reason for this high mortality rate is unclear. This may be explained by inadequate treatment due to the low awareness of this rare disease, misclassification bias inherent in code-based administrative database studies, or differences in prognosis among different populations.

\section{2) $C D$}

In contrast to UC, a meta-analysis of 9 Western populationbased cohort studies from Europe $(\mathrm{n}=8)$ and North America $(\mathrm{n}=1)$ demonstrated increased mortality from $\mathrm{CD}$ with a pooled SMR of 1.39 (95\% CI, 1.30-1.49). ${ }^{97}$ In addition, in a Danish national cohort, there was no improvement in the hazard ratio for mortality in patients with CD from 1982 to $2010 .^{93}$

In the SK-IBD cohort, the cumulative survival rates at 1, 5, 10,20 , and 30 years after CD diagnosis were $100 \%, 99.0 \%, 98.6 \%$, 98.6\%, and 84.5\%, respectively, and the SMR was 1.36 (95\% CI, 0.59-2.68).$^{30}$ In the Hong Kong IBD Registry, the SMR was 2.0 (95\% CI, 0.9-4.0). ${ }^{32}$ The SMRs in these 2 Asian studies seemed comparable to those in Western studies, although the increased mortality from CD in these 2 studies did not reach statistical significance probably due to a type II error. In contrast to these 2 Asian studies, a population-based study from Taiwan showed a remarkably increased mortality from CD (SMR, 3.72; 95\% CI, 3.02-4.55). ${ }^{42}$ The SMR in the Taiwanese patients with CD decreased from 5.46 (95\% CI, 3.38-8.43) in 2001-2005 to 2.80 
(95\% CI, 2.01-3.80) in 2011-2015. However, the SMR in the most recent cohort remained higher than that in the Western meta-analysis. Possible reasons for this high mortality were discussed in the section on UC mortality.

\section{SUMMARY AND CONCLUSION}

The results of this review suggest that the clinical course of Asian patients with IBD, especially UC, is better than that of Western patients, as indicated by the lower rates of major surgery and hospitalization. In addition, as in Western patients, the clinical course of Asian patients with IBD is improving, as evidenced by decreasing rates of disease behavior progression (in CD), hospitalization, and major surgery.

However, this study had a few limitations. First, this review contains data only from East Asia and Southeast Asia, because there are no population-based studies on the clinical course of IBD in the Middle East and South Asia. Therefore, it is unclear whether the disease outcomes of this review can be generalized to all Asian populations, considering that there is genotypic and phenotypic heterogeneity among IBD patients in different Asian populations. ${ }^{5,798}$ Second, although Asian countries have very heterogeneous medical environments, the different medical standards of each country were not considered in this review. Third, we could not reach conclusions in the case of some outcome parameters such as colorectal cancer risk and mortality rate, because these parameters need longerterm studies.

Therefore, to make a definite conclusion on the prognosis of IBD in Asian patients, more studies from different Asian countries with long-term follow-up are needed. Knowledge of the clinical course of Asian patients with IBD may help in selecting optimal treatment strategies and developing healthcare policies.

\section{ADDITIONAL INFORMATION}

\section{Funding Source}

The authors received no financial support for the research, authorship, and/or publication of this article.

\section{Conflict of Interest}

No potential conflict of interest relevant to this article was reported.

\section{Data Availability Statement}

Not applicable.

\section{Author Contribution}

Study design: Song EM, Yang SK. Performing the bibliographical research: Song EM, Yang SK. Writing the paper: Song EM, Yang SK.

\section{ORCID}

Song EM

https://orcid.org/0000-0002-2428-1551

Yang SK

\section{REFERENCES}

1. Park SH, Kim YJ, Rhee KH, et al. A 30-year trend analysis in the epidemiology of inflammatory bowel disease in the Songpa-Kangdong district of Seoul, Korea in 1986-2015. J Crohns Colitis 2019;13:1410-1417.

2. Mak WY, Zhao M, Ng SC, Burisch J. The epidemiology of inflammatory bowel disease: east meets west. J Gastroenterol Hepatol 2020;35:380-389.

3. Yen HH, Weng MT, Tung CC, et al. Epidemiological trend in inflammatory bowel disease in Taiwan from 2001 to 2015: a nationwide population-based study. Intest Res 2019;17:54-62.

4. Kaibullayeva J, Ualiyeva A, Oshibayeva A, Dushpanova A, Marshall JK. Prevalence and patient awareness of inflammatory bowel disease in Kazakhstan: a cross-sectional study. Intest Res 2020;18:430-437.

5. Thia KT, Loftus EV Jr, Sandborn WJ, Yang SK. An update on the epidemiology of inflammatory bowel disease in Asia. Am J Gastroenterol 2008;103:3167-3182.

6. Yang SK. How does the epidemiology of inflammatory bowel disease differ between East and West? A Korean perspective. Inflamm Intest Dis 2017;2:95-101.

7. Liu JZ, van Sommeren S, Huang H, et al. Association analyses identify 38 susceptibility loci for inflammatory bowel disease and highlight shared genetic risk across populations. Nat Genet 2015;47:979-986.

8. Limsrivilai J, Pausawasdi N. Intestinal tuberculosis or Crohn's disease: a review of the diagnostic models designed to differentiate between these two gastrointestinal diseases. Intest Res 2021;19:21-32.

9. Banerjee R, Pal P, Girish BG, Reddy DN. Risk factors for diagnostic delay in Crohn's disease and their impact on long-term complications: how do they differ in a tuberculosis endemic region? Aliment Pharmacol Ther 2018;47:1367-1374. 
10. Yang SK. Current status and clinical characteristics of inflammatory bowel disease in Korea. Korean J Gastroenterol 2002; 40:1-14.

11. Park SK, Choi CH, Chun J, et al. Prevention and management of viral hepatitis in inflammatory bowel disease: a clinical practice guideline by the Korean Association for the Study of Intestinal Diseases. Intest Res 2020;18:18-33.

12. Park SH, Yang SK, Lim YS, et al. Clinical courses of chronic hepatitis $B$ virus infection and inflammatory bowel disease in patients with both diseases. Inflamm Bowel Dis 2012;18:20042010.

13. Park DI, Hisamatsu T, Chen M, et al. Asian Organization for Crohn's and Colitis and Asian Pacific Association of Gastroenterology consensus on tuberculosis infection in patients with inflammatory bowel disease receiving anti-tumor necrosis factor treatment. Part 1: risk assessment. J Gastroenterol Hepatol 2018;33:20-29.

14. Hong SN, Kim HJ, Kim KH, Han SJ, Ahn IM, Ahn HS. Risk of incident Mycobacterium tuberculosis infection in patients with inflammatory bowel disease: a nationwide populationbased study in South Korea. Aliment Pharmacol Ther 2017; 45:253-263.

15. Cannon MJ, Schmid DS, Hyde TB. Review of cytomegalovirus seroprevalence and demographic characteristics associated with infection. Rev Med Virol 2010;20:202-213.

16. Park SH, Yang SK, Hong SM, et al. Severe disease activity and cytomegalovirus colitis are predictive of a nonresponse to infliximab in patients with ulcerative colitis. Dig Dis Sci 2013;58: 3592-3599.

17. Yang SK, Hong M, Baek J, et al. A common missense variant in NUDT15 confers susceptibility to thiopurine-induced leukopenia. Nat Genet 2014;46:1017-1020.

18. Matsuoka K. NUDT15 gene variants and thiopurine-induced leukopenia in patients with inflammatory bowel disease. Intest Res 2020;18:275-281.

19. Ooi CJ, Hilmi I, Banerjee R, et al. Best practices on immunomodulators and biologic agents for ulcerative colitis and Crohn's disease in Asia. Intest Res 2019;17:285-310.

20. Moroi R, Endo K, Yamamoto K, et al. Long-term prognosis of Japanese patients with biologic-naïve Crohn's disease treated with anti-tumor necrosis factor- $\alpha$ antibodies. Intest Res 2019; 17:94-106.

21. Park SH, Hwang SW, Kwak MS, et al. Long-term outcomes of infliximab treatment in 582 Korean patients with Crohn's disease: a hospital-based cohort study. Dig Dis Sci 2016;61:20602067.
22. Seo H, Chang K, Lee SH, et al. Long-term outcomes of infliximab treatment and predictors of response in 195 patients with ulcerative colitis: a hospital-based cohort study from Korea. Scand J Gastroenterol 2017;52:857-863.

23. Seo H, Ye BD, Song EM, et al. Long-term outcomes of adalimumab treatment in 254 patients with Crohn's disease: a hospital-based cohort study from Korea. Dig Dis Sci 2017;62:28822893.

24. Oh EH, Kim J, Ham N, et al. Long-term outcomes of adalimumab therapy in Korean patients with ulcerative colitis: a hospital-based cohort study. Gut Liver 2020;14:347-356.

25. Hisamatsu T, Suzuki Y, Kobayashi M, et al. Long-term safety and effectiveness of adalimumab in Japanese patients with Crohn's disease: 3-year results from a real-world study. Intest Res 2021;19:408-418.

26. Ooi CJ, Hilmi IN, Kim HJ, et al. Efficacy and safety of vedolizumab in ulcerative colitis in patients from Asian countries in the GEMINI 1 study. Intest Res 2021;19:71-82.

27. Banerjee R, Chuah SW, Hilmi IN, et al. Efficacy and safety of vedolizumab in Crohn's disease in patients from Asian countries in the GEMINI 2 study. Intest Res 2021;19:83-94.

28. Okamoto H, Dirks NL, Rosario M, Hori T, Hibi T. Population pharmacokinetics of vedolizumab in Asian and non-Asian patients with ulcerative colitis and Crohn's disease. Intest Res 2021;19:95-105.

29. Hisamatsu T, Kim HJ, Motoya S, et al. Efficacy and safety of ustekinumab in East Asian patients with moderately to severely active ulcerative colitis: a subpopulation analysis of global phase 3 induction and maintenance studies (UNIFI). Intest Res 2021;19:386-397.

30. Cha JM, Park SH, Rhee KH, et al. Long-term prognosis of ulcerative colitis and its temporal changes between 1986 and 2015 in a population-based cohort in the Songpa-Kangdong district of Seoul, Korea. Gut 2020;69:1432-1440.

31. Ng SC, Zeng Z, Niewiadomski O, et al. Early course of inflammatory bowel disease in a population-based inception cohort study from 8 countries in Asia and Australia. Gastroenterology 2016;150:86-95.

32. Ng SC, Leung WK, Shi HY, et al. Epidemiology of inflammatory bowel disease from 1981 to 2014: results from a territorywide population-based registry in Hong Kong. Inflamm Bowel Dis 2016;22:1954-1960.

33. Zhao M, Gönczi L, Lakatos PL, Burisch J. The burden of inflammatory bowel disease in Europe in 2020. J Crohns Colitis 2021;15:1573-1587.

34. Tsai L, Ma C, Dulai PS, et al. Contemporary risk of surgery in 
patients with ulcerative colitis and Crohn's disease: a metaanalysis of population-based cohorts. Clin Gastroenterol Hepatol 2021;19:2031-2045.

35. Ye BD, Hong SN, Seo SI, et al. Changes in the long-term prognosis of Crohn's disease between 1986 and 2015: the population-based Songpa-Kangdong inflammatory bowel disease cohort study. Gut Liver 2022;16:216-227.

36. Pandey A, Salazar E, Kong CS, et al. Risk of major abdominal surgery in an Asian population-based Crohn's disease cohort. Inflamm Bowel Dis 2015;21:2625-2633.

37. So J, Tang W, Leung WK, et al. Cancer risk in 2621 Chinese patients with inflammatory bowel disease: a population-based cohort study. Inflamm Bowel Dis 2017;23:2061-2068.

38. Mak WY, Mak OS, Lee CK, et al. Significant medical and surgical morbidity in perianal Crohn's disease: results from a territory-wide study. J Crohns Colitis 2018;12:1392-1398.

39. Song EM, Lee HS, Kim YJ, et al. Incidence and outcomes of perianal disease in an Asian population with Crohn's disease: a nationwide population-based study. Dig Dis Sci 2020;65: 1189-1196.

40. Wang LH, Yang YJ, Cheng WC, Wang WM, Lin SH, Shieh CC. Higher risk for hematological malignancies in inflammatory bowel disease: a nationwide population-based study in Taiwan. Am J Gastroenterol 2016;111:1313-1319.

41. Jung YS, Han M, Park S, Kim WH, Cheon JH. Cancer risk in the early stages of inflammatory bowel disease in Korean patients: a nationwide population-based study. J Crohns Colitis 2017; 11:954-962.

42. Lin WC, Weng MT, Tung CC, et al. Trends and risk factors of mortality analysis in patients with inflammatory bowel disease: a Taiwanese nationwide population-based study. J Transl Med 2019;17:414.

43. Fumery M, Singh S, Dulai PS, Gower-Rousseau C, Peyrin-Biroulet L, Sandborn WJ. Natural history of adult ulcerative colitis in population-based cohorts: a systematic review. Clin Gastroenterol Hepatol 2018;16:343-356.

44. Torres J, Billioud V, Sachar DB, Peyrin-Biroulet L, Colombel JF. Ulcerative colitis as a progressive disease: the forgotten evidence. Inflamm Bowel Dis 2012;18:1356-1363.

45. Lakatos L, Kiss LS, David G, et al. Incidence, disease phenotype at diagnosis, and early disease course in inflammatory bowel diseases in Western Hungary, 2002-2006. Inflamm Bowel Dis 2011;17:2558-2565.

46. Burisch J, Katsanos KH, Christodoulou DK, et al. Natural disease course of ulcerative colitis during the first five years of follow-up in a European population-based inception cohort: an Epi-IBD study. J Crohns Colitis 2019;13:198-208.

47. Burisch J, Ungaro R, Vind I, et al. Proximal disease extension in patients with limited ulcerative colitis: a Danish population-based inception cohort. J Crohns Colitis 2017;11:12001204.

48. Solberg IC, Lygren I, Jahnsen J, et al. Clinical course during the first 10 years of ulcerative colitis: results from a populationbased inception cohort (IBSEN Study). Scand J Gastroenterol 2009;44:431-440.

49. Roda G, Narula N, Pinotti R, et al. Systematic review with meta-analysis: proximal disease extension in limited ulcerative colitis. Aliment Pharmacol Ther 2017;45:1481-1492.

50. Eriksson C, Cao Y, Rundquist S, et al. Changes in medical management and colectomy rates: a population-based cohort study on the epidemiology and natural history of ulcerative colitis in Örebro, Sweden, 1963-2010. Aliment Pharmacol Ther 2017;46:748-757.

51. Burisch J, Kiudelis G, Kupcinskas L, et al. Natural disease course of Crohn's disease during the first 5 years after diagnosis in a European population-based inception cohort: an Epi-IBD study. Gut 2019;68:423-433.

52. Lo B, Vester-Andersen MK, Vind I, et al. Changes in disease behaviour and location in patients with Crohn's disease after seven years of follow-up: a Danish population-based inception cohort. J Crohns Colitis 2018;12:265-272.

53. Peyrin-Biroulet L, Harmsen WS, Tremaine WJ, Zinsmeister AR, Sandborn WJ, Loftus EV Jr. Surgery in a population-based cohort of Crohn's disease from Olmsted County, Minnesota (1970-2004). Am J Gastroenterol 2012;107:1693-1701.

54. Jeuring SF, van den Heuvel TR, Zeegers MP, et al. Epidemiology and long-term outcome of inflammatory bowel disease diagnosed at elderly age-an increasing distinct entity? Inflamm Bowel Dis 2016;22:1425-1434.

55. Hammer T, Nielsen KR, Munkholm P, Burisch J, Lynge E. The Faroese IBD Study: incidence of inflammatory bowel diseases across 54 years of population-based data. J Crohns Colitis 2016;10:934-942.

56. Ramadas AV, Gunesh S, Thomas GA, Williams GT, Hawthorne AB. Natural history of Crohn's disease in a population-based cohort from Cardiff (1986-2003): a study of changes in medical treatment and surgical resection rates. Gut 2010;59:12001206.

57. Zhulina Y, Udumyan R, Henriksson I, Tysk C, Montgomery S, Halfvarson J. Temporal trends in non-stricturing and non-penetrating behaviour at diagnosis of Crohn's disease in Örebro, Sweden: a population-based retrospective study. J Crohns 
Colitis 2014;8:1653-1660.

58. Shi HY, Levy AN, Trivedi HD, Chan FKL, Ng SC, Ananthakrishnan AN. Ethnicity influences phenotype and outcomes in inflammatory bowel disease: a systematic review and meta-analysis of population-based studies. Clin Gastroenterol Hepatol 2018;16:190-197.

59. Schwartz DA, Loftus EV Jr, Tremaine WJ, et al. The natural history of fistulizing Crohn's disease in Olmsted County, Minnesota. Gastroenterology 2002;122:875-880.

60. Thia KT, Sandborn WJ, Harmsen WS, Zinsmeister AR, Loftus EV Jr. Risk factors associated with progression to intestinal complications of Crohn's disease in a population-based cohort. Gastroenterology 2010;139:1147-1155.

61. Park SH, Aniwan S, Scott Harmsen W, et al. Update on the natural course of fistulizing perianal Crohn's disease in a population-based cohort. Inflamm Bowel Dis 2019;25:1054-1060.

62. Hellers G, Bergstrand O, Ewerth S, Holmström B. Occurrence and outcome after primary treatment of anal fistulae in Crohn's disease. Gut 1980;21:525-527.

63. Sjöberg D, Holmström T, Larsson M, et al. Incidence and clinical course of Crohn's disease during the first year: results from the IBD Cohort of the Uppsala Region (ICURE) of Sweden 2005-2009. J Crohns Colitis 2014;8:215-222.

64. van den Heuvel T, Jeuring S, Zeegers MP, et al. A 20-year temporal change analysis in incidence, presenting phenotype and mortality, in the Dutch IBDSL Cohort: can diagnostic factors explain the increase in IBD incidence? J Crohns Colitis 2017;11:1169-1179.

65. Jeuring SF, van den Heuvel TR, Liu LY, et al. Improvements in the long-term outcome of Crohn's disease over the past two decades and the relation to changes in medical management: results from the population-based IBDSL cohort. Am J Gastroenterol 2017;112:325-336.

66. Lakatos PL, Golovics PA, David G, et al. Has there been a change in the natural history of Crohn's disease? Surgical rates and medical management in a population-based inception cohort from Western Hungary between 1977-2009. Am J Gastroenterol 2012;107:579-588.

67. Göttgens KW, Jeuring SF, Sturkenboom R, et al. Time trends in the epidemiology and outcome of perianal fistulizing Crohn's disease in a population-based cohort. Eur J Gastroenterol Hepatol 2017;29:595-601.

68. Bernell O, Lapidus A, Hellers G. Risk factors for surgery and postoperative recurrence in Crohn's disease. Ann Surg 2000; 231:38-45.

69. Samuel S, Ingle SB, Dhillon S, et al. Cumulative incidence and risk factors for hospitalization and surgery in a populationbased cohort of ulcerative colitis. Inflamm Bowel Dis 2013; 19:1858-1866.

70. Aniwan S, Limsrivilai J, Pongprasobchai S, et al. Temporal trend in the natural history of ulcerative colitis in a country with a low incidence of ulcerative colitis from 2000 through 2018. Intest Res 2021;19:186-193.

71. Ingle SB, Loftus EV, Harmsen SW, et al. Hospitalization rates for Crohn's disease patients in Olmsted county, Minnesota, in the pre-biologic era. Am J Gastroenterol 2007;102:S487.

72. Rahman A, Jairath V, Feagan BG, et al. Declining hospitalisation and surgical intervention rates in patients with Crohn's disease: a population-based cohort. Aliment Pharmacol Ther 2019;50:1086-1093.

73. Jess T, Rungoe C, Peyrin-Biroulet L. Risk of colorectal cancer in patients with ulcerative colitis: a meta-analysis of population-based cohort studies. Clin Gastroenterol Hepatol 2012; 10:639-645.

74. Winther KV, Jess T, Langholz E, Munkholm P, Binder V. Longterm risk of cancer in ulcerative colitis: a population-based cohort study from Copenhagen County. Clin Gastroenterol Hepatol 2004;2:1088-1095.

75. Lakatos L, Mester G, Erdelyi Z, et al. Risk factors for ulcerative colitis-associated colorectal cancer in a Hungarian cohort of patients with ulcerative colitis: results of a population-based study. Inflamm Bowel Dis 2006;12:205-211.

76. Söderlund S, Brandt L, Lapidus A, et al. Decreasing time-trends of colorectal cancer in a large cohort of patients with inflammatory bowel disease. Gastroenterology 2009;136:1561-1567.

77. Jess T, Simonsen J, Jørgensen KT, Pedersen BV, Nielsen NM, Frisch M. Decreasing risk of colorectal cancer in patients with inflammatory bowel disease over 30 years. Gastroenterology 2012;143:375-381.

78. Kappelman MD, Farkas DK, Long MD, et al. Risk of cancer in patients with inflammatory bowel diseases: a nationwide population-based cohort study with 30 years of follow-up evaluation. Clin Gastroenterol Hepatol 2014;12:265-273.

79. Lee HS, Park SH, Yang SK, et al. The risk of colorectal cancer in inflammatory bowel disease: a hospital-based cohort study from Korea. Scand J Gastroenterol 2015;50:188-196.

80. Kishikawa J, Hata K, Kazama S, et al. Results of a 36-year surveillance program for ulcerative colitis-associated neoplasia in the Japanese population. Dig Endosc 2018;30:236-244.

81. Gong W, Lv N, Wang B, et al. Risk of ulcerative colitis-associated colorectal cancer in China: a multi-center retrospective study. Dig Dis Sci 2012;57:503-507. 
82. Wei SC, Shieh MJ, Chang MC, Chang YT, Wang CY, Wong JM. Long-term follow-up of ulcerative colitis in Taiwan. J Chin Med Assoc 2012;75:151-155.

83. Jess T, Gamborg M, Matzen P, Munkholm P, Sørensen TI. Increased risk of intestinal cancer in Crohn's disease: a metaanalysis of population-based cohort studies. Am J Gastroenterol 2005;100:2724-2729.

84. Mizushima T, Ohno Y, Nakajima K, et al. Malignancy in Crohn's disease: incidence and clinical characteristics in Japan. Digestion 2010;81:265-270.

85. Yano Y, Matsui T, Hirai F, et al. Cancer risk in Japanese Crohn's disease patients: investigation of the standardized incidence ratio. J Gastroenterol Hepatol 2013;28:1300-1305.

86. Lutgens MW, van Oijen MG, van der Heijden GJ, Vleggaar FP, Siersema PD, Oldenburg B. Declining risk of colorectal cancer in inflammatory bowel disease: an updated meta-analysis of population-based cohort studies. Inflamm Bowel Dis 2013; 19:789-799.

87. Zeng Z, Zhu Z, Yang Y, et al. Incidence and clinical characteristics of inflammatory bowel disease in a developed region of Guangdong Province, China: a prospective population-based study. J Gastroenterol Hepatol 2013;28:1148-1153.

88. Höie O, Schouten LJ, Wolters FL, et al. Ulcerative colitis: no rise in mortality in a European-wide population based cohort 10 years after diagnosis. Gut 2007;56:497-503.

89. Hovde Ø, Småstuen MC, Høivik ML, et al. Mortality and causes of death in ulcerative colitis: results from 20 years of follow-up in the IBSEN study. Inflamm Bowel Dis 2016;22:141-145.

90. Romberg-Camps M, Kuiper E, Schouten L, et al. Mortality in inflammatory bowel disease in the Netherlands 1991-2002: results of a population-based study. The IBD South-Limburg cohort. Inflamm Bowel Dis 2010;16:1397-1410.

91. Manninen P, Karvonen AL, Huhtala H, et al. Mortality in ulcerative colitis and Crohn's disease: a population-based study in Finland. J Crohns Colitis 2012;6:524-528.

92. Caini S, Bagnoli S, Palli D, et al. Total and cancer mortality in a cohort of ulcerative colitis and Crohn's disease patients: the Florence inflammatory bowel disease study, 1978-2010. Dig Liver Dis 2016;48:1162-1167.

93. Jess T, Frisch M, Simonsen J. Trends in overall and cause-specific mortality among patients with inflammatory bowel disease from 1982 to 2010. Clin Gastroenterol Hepatol 2013;11: 43-48.

94. Bitton A, Vutcovici M, Sewitch M, Suissa S, Brassard P. Mortality trends in Crohn's disease and ulcerative colitis: a population-based study in Québec, Canada. Inflamm Bowel Dis 2016; 22:416-423.

95. Aniwan S, Harmsen WS, Tremaine WJ, Kane SV, Loftus EV Jr. Overall and cause-specific mortality of inflammatory bowel disease in Olmsted County, Minnesota, from 1970 through 2016. Mayo Clin Proc 2018;93:1415-1422.

96. Jess T, Gamborg M, Munkholm P, Sørensen TI. Overall and cause-specific mortality in ulcerative colitis: meta-analysis of population-based inception cohort studies. Am J Gastroenterol 2007;102:609-617.

97. Duricova D, Pedersen N, Elkjaer M, Gamborg M, Munkholm P, Jess T. Overall and cause-specific mortality in Crohn's disease: a meta-analysis of population-based studies. Inflamm Bowel Dis 2010;16:347-353.

98. Ng WK, Wong SH, Ng SC. Changing epidemiological trends of inflammatory bowel disease in Asia. Intest Res 2016;14:111119. 